\title{
Predicting Nail Withdrawal Resistance and Bearing Strength of Cross-laminated Timbers from Mixed Species
}

\begin{abstract}
Keonho Kim *
The increasing demand for sustainable architecture has led to a growing interest in wood structures. Hence, ensuring their structural stability and strength performance is an imperative. This study investigated the nail bearing strength and withdrawal resistance of mixed cross-laminated timber (CLT) using Japanese larch and yellow poplar layers. The mixed CLT was composed of three larch laminas (major) and two yellow poplar laminas (minor). The bearing strength of the mixed CLT decreased as the ratio of the thickness of the minor lamina to nail depth increased. The nail withdrawal resistance differed in the penetration and axial directions of the laminas. In the direction perpendicular to the grain, the withdrawal resistance load of the yellow poplar lamina was measured to be 1.45-times that of the larch lamina. The withdrawal resistance of the mixed CLT with the yellow poplar layer was $17 \%$ higher than that with larch. Therefore, the length of the nail used for the mixed CLT should be selected based on the thickness of the minor lamina to achieve efficient bearing and withdrawal resistance of the nail connection.
\end{abstract}

Keywords: Cross-laminated timber; Nail connection; Bearing strength; Nail withdrawal resistance; Yellow poplar; Mixed composition

Contact information: Department of Forest Products, National Institute of Forest Science, Republic of Korea; Email:keon@korea.kr

\section{INTRODUCTION}

The use of eco-friendly building materials is drawing interest as buildings and architectural styles become sustainable. The use of woods as building materials is a promotional strategy aimed at realizing net-zero emissions in the Korea Forest Service. Among these, wood is used as a structural member for light frames or heavy timber structures. Wooden structures have increased in size with the development of engineered wood, such as glulam, parallel-strand lumber, and laminated veneer lumber. Recently, cross-laminated timber (CLT), a structural panel, has been developed to accelerate the construction of high-rise wooden buildings. CLT was first used in Europe and North America, where it was applied to shear walls or floors as structural panels with orthogonal layers of graded laminas (Erol and Sylvain 2019). Studies on the bending performance of CLT have reported the influence of major axial laminas on its modulus of elasticity. Moreover, CLT failure is attributed to the rolling shear failure of its minor layer. Yellow poplar, as a fast-growing tree, is much used as a biofuel in South Korea, but studies into its use in high value-added glulam or CLT have been conducted in North America (Moody et al. 1993). With studies showing that hardwood with a low specific gravity can be used as inner layer materials, a study on the bonding quality of CLT with mixed species is necessary to ensure adhesion performance for structural members (Larkin et al. 2016; Kim 
and Jeon 2019). Reports that show applicable adhesion performance according to the lamina species for domestic CLTs are currently available (Park et al. 2017; Mahdavifar et al. 2019; Norwahyuni et al. 2019; Kim 2020).

The structural design of a CLT shear wall connection can be predicted by the mechanical properties of the fastener, the connection assemblies, and the CLT. Generally, high-rigidity CLT wall and floor connections can easily be assembled using steel through brackets and hold-downs, among others. Nail connections, such as ring and screw nails, are commonly used for CLT assemblies. The European yield model (EYM) formula adapted by the National Design Specification (NDS; American Society of Civil Engineering 2005) is used to design connections in wooden structures. The bending strength of the fastener and the bearing performance of the wood material are important factors for the EYM formula of the reference allowable lateral strength. In addition, it is noted that the failure mode of the connection can be determined if:

- The side member, with poorer bearing properties than the main member, fails by breakage of the fastener (Failure mode 1);

- The side member fails by breakage of the fastener (Failure mode 2);

- The fastener is bent by the main member, and the side member then fails accordingly by breakage of the fastener (Failure mode 3 ); and

- The connection fails by breakage of the main member, but the side member does not fail (Failure mode 4).

The reference allowable shear strength uses the lowest predicted EYM values for failure modes according to KDS 413305 (Korean Institute for Development Strategy 2016). The bearing strength of wood is affected by the density of the wood and the fastener diameter according to the load direction (Wilkinson 1991). Rammer and Winistorfer (2001) compared the bearing strengths of woods with five different moisture rates, and reported an increase in the bearing strength with decreasing moisture content. Based on the NDS and KDS guidelines, the bearing strength of wood is calculated using the nail diameter and species density; hence, the layer species and the CLT composition are important calculational factors. Kim and Hong (2008) reported that the bearing strength of a structural larch glulam parallel to the grain is approximately 1.61-times that perpendicular to the grain. Increasing the fastener diameter from $12 \mathrm{~mm}$ to $20 \mathrm{~mm}$ also increased bearing performance. For CLT laminated perpendicular to the layer grains, a reduction factor on the bearing area is required to predict bearing strength because the bearing area of the CLT depends on the load direction even within the same species composition. The NDS guidelines suggest that the predicted bearing strength that reflects the mechanical characteristics of a CLT should be multiplied by 0.67 as the CLT factor.

The withdrawal resistance of nails from wood depends on the tree type, the specific gravity of the wood, the penetration orientation, and the shape and diameter of the nail, among others (Cha 2002; Rammer and Zelinka 2004; Mahdavifar et al. 2018). Nail withdrawal resistance performance is important when designing CLT connections for shear walls or edges. When cyclic loads, such as earthquakes, are applied, the nail withdrawal resistance decreases rapidly. The abrupt stress of a pulse from an earthquake can alter the situation. Prior to the pulse, the structure depends on static friction between the wood and the nail, while the structure may depend on sliding friction immediately after the pulse. In general, the withdrawal resistance of a nail under static loading is higher than that under dynamic loading (Broker and Krause 1991). Noguchi and Sugihara (1961) reported that the withdrawal resistance of nails driven by static loading is higher than the impact load.

Kim (2021). "Nail withdrawal resistance of CLT," BioResources 16(2), 4027-4038.

4028 
As proposed by the NDS, nail withdrawal resistance is classified for ordinary nails, screw nails, and leg screws. A prediction formula is proposed based on the specific gravity and penetration direction with respect to the layer grains. For a hardwood-based mixed CLT, the proportion of the hardwood layer to the nail penetration depth influences the nail withdrawal resistance.

In this study, bearing strength and nail withdrawal resistance performance were tested according to the grain direction of the layers of the mixed CLT for nail connections. The mixed CLT layers are composed of Japanese larch and yellow poplar for high valueadded utilization. The predicted and experimental values of the bearing and nail withdrawal resistance strengths were compared to determine the mechanical properties of the layer.

\section{EXPERIMENTAL}

\section{Materials and CLT Manufacturing}

The CLT laminas were $100 \mathrm{~mm}$ wide and $25 \mathrm{~mm}$ thick and were made from domestic Japanese larch (Larix kaempferi Carr.) and yellow poplar (Liriodendron tulipifera L.) by the National Forestry Cooperative Federation. The average moisture contents of the Japanese larch and yellow poplar lamina were $10.5 \%$ and $11.5 \%$, respectively, with specific gravities (S.G.s) of 0.54 and 0.48 , respectively. The CLT was fabricated by gluing alternate layers oriented perpendicular to the adjacent layer in a symmetrical manner and was composed of two major layers in parallel and a minor layer perpendicular to the longitudinal direction; they were divided into Japanese larch CLT (henceforth, larix CLT) and mixed CLT. Larix CLT employed Japanese larch laminas for all the layers, whereas the mixed CLT consisted of yellow poplar laminas (henceforth, poplar lamina) for the minor layers. Phenol-resorcinol adhesives (PRX350BT/PR-1HSE, Aica Kogyo Co., Ltd., Nagoya, Japan), water polymer isocyanate adhesives (AUX500/AUH-8, Aica Kogyo Co., Ltd., Nagoya, Japan), and isocyanate polyurethane adhesives (OCUA 970, Daehan Polymer Corp., Seoul, Korea) were used to laminate the CLTs. A clamping system (Kyoungmin Co., Ltd., Incheon, Korea) with an applied pressure of $0.1 \mathrm{MPa}$ was used to manufacture the CLTs. The resulting CLTs were $300 \mathrm{~mm}$ wide, $75 \mathrm{~mm}$ thick, and $3600 \mathrm{~mm}$ long. Ring nails are commonly used for CLT nail connections. In this study, 4-mm-diameter and 6-mm-long ring nails (LBA460, Rothoblass, Cortaccia, Italy) were used as fasteners.

\section{Bearing performance test}

The bearing performance of the mixed CLT was evaluated in accordance with KS F 2156 (2017). The bearing test specimen was cut to $100 \mathrm{~mm} \times 100 \mathrm{~mm}$ from the manufactured CLT. After setting it by pressing two manufactured CLT test specimens, a 3-mm-diameter half hole was drilled to embed the nail ring. Unlike bolts and drift pins, producing nailed bearing specimens using species with high specific gravities is extremely difficult. Therefore, the bearing strength of the non-drilled specimen was also measured and compared with that of the specimen with the drilled half holes. A bearing load was applied parallel to the grain of the major layer, and the embedment was measured by the change in the crosshead distance of a universal testing machine (Instron 5585, Instron, Norwood, USA). The bearing test was performed until the maximum load was reached within $60 \pm 30 \mathrm{~s}$ or until the embedment of the specimen was measured to be half the diameter of the ring nail. Figure 1 shows the schematic of the bearing test. 


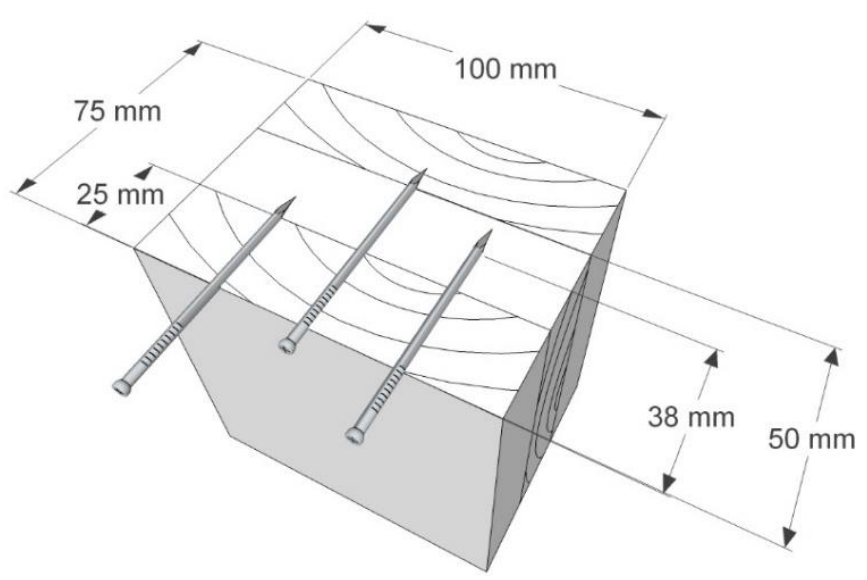

Fig. 1. Schematic of the bearing test. The types of the bearing specimens were classified by the embedded areas of the species on the loading direction to the grain: Type-A denotes larch (II) $100 \%$, Type- B denotes larch (II) $50 \%$ + poplar $(\perp) 50 \%$, and Type-C denotes larch (II) $66 \%+$ poplar $(\perp) 34 \%$. The loading directions $\|$ and $\perp$ are the directions parallel and perpendicular to the grain, respectively.

The yield-bearing strength refers to a 5\% offset bearing load per unit area measured experimentally and calculated following Eq. 1 ,

Bearing stress $=P /(L \times D)$

where the bearing stress is in $\mathrm{N} / \mathrm{mm}^{2}, P$ is the $5 \%$ offset bearing load $(\mathrm{N}), L$ denotes the embedded length of the ring nail $(\mathrm{mm})$, and $D$ denotes the diameter of the ring nail $(\mathrm{mm})$. Following the method described in KS F 2156 (2017), a 5\% offset bearing load was obtained as shown in Fig. 2. With a rapid increase or decrease in the bearing load after the yield point, the $2 \%$ offset line was moved parallel to the load-embedment curve and a $2 \%$ offset yield load was used.



Fig. 2. Bearing load-embedment curve obtained following the method in KS F 2156 (2017). Here, $P_{0.1}, P_{0.4}: 10 \%, 40 \%$ of $P_{\max }$, and $P_{5 \%}: 5 \%$ offset bearing load. 


\section{Nail withdrawal test}

The nail withdrawal resistance test based on the lamina species and nail penetration direction was conducted in accordance with KS F ISO 9087 (2014). The mixed CLT was cut to dimensions of $10 \mathrm{~cm} \times 10 \mathrm{~cm}$. Test specimen classifications are shown in Table 1 . A 3-mm-diameter hole was drilled for the ring nail. According to NDS, the spacing of the ring nails on the CLT surface is equal to $4 D$ and the end surface distance is equal to $7 D$, where $D$ is the nail diameter. For this test, the spacing between the ring nails was set to $40 \mathrm{~mm}$. The ring nail was embedded to a depth of $40 \mathrm{~mm}$, which is $2 / 3$ of the nail length (including the thread, except the pointed end). The directions of the nail penetration are shown in Table 1.

Table 1. Configurations and Nomenclature for CLT Specimens

\begin{tabular}{|c|c|c|c|c|c|c|}
\hline \multirow{2}{*}{\multicolumn{2}{|c|}{ Category }} & \multicolumn{5}{|c|}{ Penetration of Fastener ${ }^{11}$} \\
\hline & & \multicolumn{2}{|c|}{ Horizontal to the Grain } & \multicolumn{3}{|c|}{ Vertical to the Grain } \\
\hline \multirow{2}{*}{\multicolumn{2}{|c|}{ Species of the Layers }} & $\begin{array}{l}\text { Japanese } \\
\text { Larch }\end{array}$ & $\begin{array}{l}\text { Yellow } \\
\text { Poplar }\end{array}$ & $\begin{array}{l}\text { Japanese } \\
\text { Larch }\end{array}$ & $\begin{array}{l}\text { Yellow } \\
\text { Poplar }\end{array}$ & $\begin{array}{l}\text { Mixed } \\
\text { Layers }\end{array}$ \\
\hline & & LH & YH & LV & YV & MV \\
\hline \multirow{3}{*}{ Adhesive } & PRF $^{2)}$ & PRLH & $\mathrm{PRYH}$ & PRLV & PRYV & PRMV \\
\hline & PUR $^{3)}$ & PULH & PUYH & PULV & PUYV & PUMV \\
\hline & AUX ${ }^{4)}$ & AULH & AUYH & AULV & AUYV & AUMV \\
\hline
\end{tabular}

The speed of load withdrawal was set such that the nail can be pulled out after 1.0 to 2.0 min of loading. The nail withdrawal resistance $\left(\sigma_{\mathrm{w}}\right)$ was calculated using Eq. 2,

$$
\sigma_{\mathrm{w}}=F_{\max } / l
$$

where $\sigma_{\mathrm{w}}$ is the nail withdrawal resistance $(\mathrm{N} / \mathrm{mm}), F_{\max }$ is the maximum withdrawal load $(\mathrm{N})$, and $l$ is the nail penetration depth $(\mathrm{mm})$.

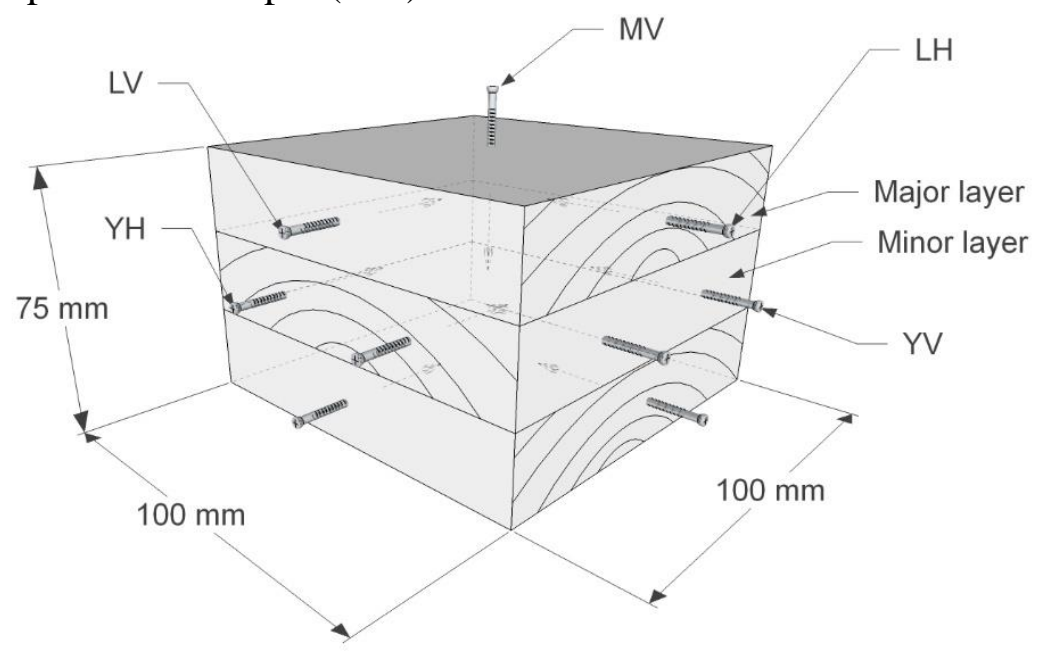

Fig. 3. Method of producing the test specimens with a semicircular groove. The letters denote the penetration direction and layer species, i.e., L: Japanese larch, Y: yellow poplar, M: Japanese larch and yellow poplar; and $\mathrm{H}$ : horizontal, $\mathrm{V}$ : vertical 


\section{RESULTS AND DISCUSSION}

\section{Bearing Strength Properties of Mixed CLT}

The bearing strength of the mixed CLT was compared to the ratio of the layer composition on the bearing area. The average bearing strength of Type-A, composed only of Japanese larch laminas was measured to be $51.71 \mathrm{MPa}$. This result is similar to the bearing strength of the drift pin of domestic Japanese larch collectibles (Hong and Park 2008). The bearing strength of Type-B, composed of a Japanese larch laminas and yellow poplar laminas, was approximately $13 \%$ less than that of Type-A. The bearing strength of Type-C, comprising Japanese larch laminas and half of the yellow poplar laminas, was approximately $10 \%$ less than that of Type-A. The bearing properties differ because the bearing strength of wood is directly proportional to the wood density and inversely proportional to the diameter of the connection (Wilkinson 1991; Sawata and Yasumura 2002; Kim and Hong 2008). Thus, the composition ratios of the laminas of low-density species as inner layers in mixed CLTs affect their overall bearing strengths. Therefore, the thickness of the larch layer, as the outermost layer of the mixed CLT and where the lateral load is applied, should be calculated to ensure efficient bearing performance of the nail. Because it is difficult to prepare pre-drilled specimens with small diameters, the bearing strengths of specimens with and without half holes were compared. For Type-A, the bearing strength differed slightly according to this preparation, while those of Types- B and $\mathrm{C}$ were $14 \%$ and $6 \%$ lower, respectively.

\section{Predicting Nail Bearing Strength}

The bearing strengths of engineered wood products are generally estimated by the specific gravities of their structural members and the fastener diameter (Whale and Smith 1989; Sawata and Yasumura 2002). For a bolt connection, the bearing strength is affected by the loading direction of the grain. However, the loading direction did not affect the bearing strengths of nails, which are narrower than bolts. Soltis et al. (1986) tested the bearing performance of bolts of various diameters based on the specific gravity of wood and the loading direction to the grain. Because there was no remarkable difference in the bearing performance based on the loading direction, a general prediction equation of bearing strength that was independent of loading direction was proposed and adopted by NDS. In South Korea, the Korean Building Code (KBC) proposed a prediction method using the specific gravity of the members and the loading direction. The prediction formula adopted in Eurocode5 (EC5), proposed by Whale and Smith (1989), was used to evaluate the bearing performance of nails and bolts with diameters of between $2.65 \mathrm{~mm}$ and $20 \mathrm{~mm}$. For the NDS standard in North America, the bearing strength of wood with a $4 \mathrm{~mm}$ diameter nail was evaluated without considering the loading direction. For CLT layers made of the same species, the bearing strength was calculated as it were an isotropic material, even when orthogonally laminated. The prediction formulas for nail bearing strength are shown in Table 2.

The bearing strengths of the mixed CLT, as estimated by the prediction equations, differ from those obtained experimentally. For Type-A, the predicted bearing strengths proposed by NDS, KBC, and EC5 are 31\%, 30\%, and 19\% lower than the experimental values, respectively. For Types- B and $\mathrm{C}$, the predicted values are calculated to be smaller than the experimental values, with EC5 providing results closest to the experimental values. 
Table 2. Prediction Equations of the Bearing Strength of Wood

\begin{tabular}{|c|c|c|c|}
\hline $\begin{array}{l}\text { Building } \\
\text { Code }\end{array}$ & NDS $^{1)}$ & $\mathrm{KBC}^{2)}$ & Eurocode 5 \\
\hline $\begin{array}{l}\text { Bearing strength formula } \\
\qquad \mathrm{Fe}^{3)}\end{array}$ & $114.5 G^{1.84}$ & $117 G^{1.84}$ & $\begin{array}{c}0.082 d^{-0.3} \rho \text { (Non pre- } \\
\text { drilled) } \\
0.082(1-0.01 d) \rho \text { (Pre- } \\
\text { drilled) }\end{array}$ \\
\hline
\end{tabular}

To optimally predict the bearing strength of the mixed CLT with the axially symmetrical composition, an experimental formula was derived from the bearing strength and thickness ratios of the laminas. Assuming equal thickness and layer compositions of the larix and mixed CLT, a reduction factor based on the bearing strength of the larch CLT was calculated using a minor axial lamina with a density less than that of Japanese larch. The thickness of the yellow poplar lamina $\left(t_{\mathrm{Y}}\right)$ was calculated by the transformed section method using the bearing strength ratio $\left(C_{\mathrm{e}}\right)$ of the larch $\left(F_{\mathrm{e}, \mathrm{L}}\right)$ and poplar laminas $\left(F_{\mathrm{e}, \mathrm{Y}}\right)$. Considering dimensional variability, the thickness of the mixed CLT ( $t_{\mathrm{M}, \mathrm{CLT})}$ was recalculated by reflecting the thickness ratio $\left(C_{\mathrm{t}}\right)$ of the larix lamina $\left(t_{\mathrm{L}}\right)$ and yellow poplar lamina ( $\left.t_{\mathrm{Y}}\right)$, as represented by Eqs. 3 to 5 :

$$
\begin{aligned}
& t_{\mathrm{M}, \mathrm{CLT}}=t_{\mathrm{L}}+t_{\mathrm{Y}} \times C_{\mathrm{e}} \times C_{\mathrm{t}}=\left(1+C_{\mathrm{e}} \times C_{\mathrm{t}}\right) \\
& C_{\mathrm{e}}=F_{\mathrm{e}, \mathrm{Y}} / F_{\mathrm{e}, \mathrm{L}} \\
& C_{\mathrm{t}}=t_{\mathrm{Y}} / t_{\mathrm{L}}
\end{aligned}
$$

The reduction factor $\left(k_{\mathrm{CLT}}\right)$ and the bearing strength prediction $\left(F_{\mathrm{e}, \mathrm{MCLT}}\right)$ of the mixed CLT were derived as follows:

$$
\begin{aligned}
& F_{\mathrm{e}, \mathrm{MCLT}}=F_{\mathrm{e}, \mathrm{L}} \times k_{\mathrm{e}, \mathrm{CLT}} \\
& k_{\mathrm{e}, \mathrm{CLT}}=\left(1+C_{\mathrm{e}} \times C_{\mathrm{t}}\right) /\left(1+C_{\mathrm{t}}\right)
\end{aligned}
$$

\begin{tabular}{|c|c|c|c|c|c|c|c|c|c|}
\hline \multirow{5}{*}{\multicolumn{2}{|c|}{ CLT Layers }} & \multirow{5}{*}{$\begin{array}{c}\text { Ratio of } \\
\text { Yellow Poplar }\end{array}$} & \multicolumn{7}{|c|}{ Bearing Strength } \\
\hline & & & \multirow{2}{*}{\multicolumn{2}{|c|}{$\begin{array}{c}\text { Experimental Value } \\
\text { Hole Type }\end{array}$}} & \multirow{2}{*}{\multicolumn{2}{|c|}{$\begin{array}{l}\text { Estimated } \\
\text { Value }\end{array}$}} & \multirow{2}{*}{\multicolumn{3}{|c|}{ Predicted Value }} \\
\hline & & & & & & & & & \\
\hline & & & Free & Half & $F_{\mathrm{e}, \mathrm{MCLT}}$ & \multirow{2}{*}{$\frac{k_{\mathrm{CLT}}}{-}$} & NDS & KBC & EC5 \\
\hline & & & \multicolumn{3}{|c|}{ (MPa) } & & \multicolumn{3}{|c|}{ (MPa) } \\
\hline $\begin{array}{l}\text { Japanese } \\
\text { Larch }\end{array}$ & A & 0.00 & $\begin{array}{l}51.88 \\
(0.02)^{1)}\end{array}$ & $\begin{array}{l}51.71 \\
(0.12)\end{array}$ & 51.71 & 1.00 & \multirow{3}{*}{35.59} & \multirow{3}{*}{36.38} & \multirow{3}{*}{41.72} \\
\hline \multirow{2}{*}{$\begin{array}{l}\text { Mixed } \\
\text { CLT }\end{array}$} & B & 0.50 & $\begin{array}{l}37.57 \\
(0.04) \\
\end{array}$ & $\begin{array}{l}43.83 \\
(0.08) \\
\end{array}$ & 44.35 & 0.86 & & & \\
\hline & C & 0.38 & $\begin{array}{c}43.3 \\
(0.03)\end{array}$ & $\begin{array}{c}46.3 \\
(0.09)\end{array}$ & 46.80 & 0.91 & & & \\
\hline
\end{tabular}

The predicted bearing strength applied to $k_{\mathrm{CLT}}$ was similar to that of the experimental bearing strength and tended to increase as the thickness ratio of the yellow poplar lamina decreased.

Table 3. Comparison of the Bearing Strengths of Larch and Mixed CLT

${ }^{1)}$ Numbers in parenthesis represent standard deviations 


\section{Nail Withdrawal Resistance}

Because the direction of nail penetration depends on the construction method, the nail withdrawal resistance was compared for various layer orientations of the mixed CLT. To extend the wall connection to the wall area, the nail penetrates vertically to the face sections of the layers. Nail penetration at the edge connection of CLT walls was horizontally driven to the minor lamina or vertically to the major lamina.

According to the lamina species, the average nail withdrawal resistance of the yellow poplar was measured to be $67.0 \mathrm{~N} / \mathrm{mm}$, which is approximately 1.45 -times that of the Japanese larch. For the mixed CLT, the average withdrawal resistance was about $17 \%$ higher than that of the Japanese larch but was approximately about $19 \%$ lower than that of the yellow poplar. Therefore, we recommend that the nail connections of the mixed CLT with yellow poplar as the minor layer penetrate as far as the yellow poplar layer to improve nail withdrawal resistance.

The ratio of the nail withdrawal resistances in the horizontal and vertical directions to the grain of the laminas were 0.57 for Japanese larch and 0.40 for yellow poplar. Gahagan and Scholten (1938) reported nail withdrawal resistance ratios of 0.58 and 0.75 for western larch (S.G. 0.58) and yellow poplar (S.G. 0.42), respectively, which were obtained by performance testing common and cement-coated nails withdrawn in the nailpenetration direction. The horizontal-penetration nail withdrawal resistances values are similar for Japanese larch and yellow poplar lamina; however, Japanese larch, which has a distinct boundary between early and late wood, had a higher coefficient of determination of withdrawal load than the yellow poplar. There was no difference in the nail withdrawal resistance performance of the mixed CLT based on the adhesive.

The reference withdrawal resistance of the ring shank nail proposed by NDS was calculated using Eq. 8, where the penetration direction of the nail is vertical to the grain, and the design value is calculated by multiplying the load duration, wet service, temperature, and end grain factors.

$$
\mathrm{W}=1380 G^{5 / 2} D W=1380 G^{5 / 2} D
$$

In Eq. 8, $W$ is the reference nail withdrawal resistance $(\mathrm{N} / \mathrm{mm}), G$ is the specific gravity, and $D$ is the nail diameter $(\mathrm{mm})$.

If the nail penetration direction is horizontal to the axial lamina, an end-grain factor $\left(C_{\text {eg }}\right)$ of 0 should be applied. The predicted reference nail withdrawal resistance was determined by multiplying the 10 -min load duration factor $C_{\mathrm{d}}(1.6)$ with the experimental value.

The predicted performance of the nail withdrawal resistance in the vertical direction of the grain was calculated by reducing the experimental value by $50 \%$ for larch and $74 \%$ for the yellow-poplar. Mohammad et al. (2009) evaluated the nail withdrawal resistance performance of poplar using screw nails and compared it with the NDS predicted value; the experimental value was measured to be $25 \%$ higher than the predicted value. Eckelman (1975) reported that the nail withdrawal resistance performance of a hardwood is more important to shear strength in the grain direction than the specific gravity of the wood.

The nail resistance performance of the mixed CLT was predicted by the withdrawal resistance properties of the layer obtained in this study. The CLT coefficient ( $\left.k_{\mathrm{w}, \mathrm{CLT}}\right)$ is driven by the ratio of the nail withdrawal resistance performance $\left(C_{\mathrm{w}}\right)$ of the lamina species and the ratio of the effective penetration depth $\left(C_{\mathrm{t}}\right)$ of the layers on the mixed CLT. The effective depth of the CLT penetration $\left(l_{\mathrm{CLT}}\right)$ in the vertical direction to the grain was calculated by the effective depth of the Japanese larch $\left(l_{\mathrm{L}}\right)$ and yellow poplar lamina $\left(l_{\mathrm{Y}}\right)$ 
and was used to predict the nail withdrawal resistance performance ( $W_{\text {CLT }}$ ) of the mixed CLT. Equations 9 through 14 are as follows,

$$
\begin{aligned}
& W=F_{\mathrm{w}} l_{\mathrm{w}} \\
& W_{\mathrm{CLT}} l_{\mathrm{CLT}}=W_{\mathrm{L}} l_{\mathrm{L}}+W_{\mathrm{Y}} l_{\mathrm{Y}} \\
& W_{\mathrm{CLT}}=W_{\mathrm{L}} \times k_{\mathrm{W}, \mathrm{CLT}} \\
& C_{W}=F_{\mathrm{W}, \mathrm{Y}} / F_{\mathrm{W}, \mathrm{L}} \\
& C_{l}=l_{\mathrm{Y}} / l_{\mathrm{L}} \\
& k \mathrm{~W}, \mathrm{CLT}=\left(l_{\mathrm{L}} / l_{\mathrm{CLT}}\right)\left(1+C_{\mathrm{W}} C_{1}\right)
\end{aligned}
$$

where $W$ is the nail withdrawal resistance $(\mathrm{N} / \mathrm{mm})$ with subscripts $C L T$ for CLT, $L$ for Japanese larch, and $Y$ for yellow poplar; $F_{\mathrm{W}}$ is the withdrawal load $(\mathrm{N}) ; l_{\mathrm{W}}$ is the effective depth of the nail penetration (mm); and $k_{\mathrm{W}, \mathrm{CLT}}$ is the CLT coefficient for nail withdrawal resistance.

The predicted nail withdrawal resistance values using the withdrawal properties of laminas was similar to the experimental values of the mixed CLT. Based on KS F ISO 9087 (2014), the penetration depth of a nail is proposed to be $3 / 4$ of the nail length. However, for the mixed CLT, the nail withdrawal resistance performance should be studied using various effective lengths. In addition, verifying the mechanical performance of different types of material layer is essential for predicting CLT strength.

\begin{tabular}{|c|c|c|c|c|}
\hline \multirow{2}{*}{\multicolumn{2}{|c|}{ Direction of Nail Penetration }} & \multicolumn{3}{|c|}{ Nail Withdrawal Resistance ( $/ \mathrm{mm})$} \\
\hline & & \multirow{2}{*}{$\begin{array}{c}\begin{array}{c}\text { Major Layer } \\
\left.\left(W_{\mathbf{L}} W_{\mathrm{L}}\right)\right)\end{array} \\
46.18 \\
(0.26)\end{array}$} & \multirow{2}{*}{$\begin{array}{c}\begin{array}{c}\text { Minor Layer } \\
\left(W_{\mathbf{Y}}\right) \boldsymbol{W}_{\mathbf{Y}}\end{array} \\
66.99 \\
(0.25)\end{array}$} & \multirow{2}{*}{$\begin{array}{c}\text { Mixed Layers } \\
\left.\text { ( } \boldsymbol{W}_{\mathrm{CLT}}\right) \boldsymbol{W}_{\text {CLT }} \\
54.18 \\
(0.39)\end{array}$} \\
\hline \multirow{2}{*}{$\begin{array}{l}\text { Perpendicular to } \\
\text { the grain }\end{array}$} & Exp. & & & \\
\hline & Predicted & $23.15^{1)}$ & $22.86^{1)}$ & $53.98^{21}$ \\
\hline $\begin{array}{l}\text { Parallel to the } \\
\text { grain }\end{array}$ & Exp. & $\begin{array}{l}26.61 \\
(0.53)\end{array}$ & $\begin{array}{l}26.90 \\
(0.27)\end{array}$ & $0.00^{*}$ \\
\hline
\end{tabular}

Table 4. Nail Withdrawal Resistances on the Direction of the Nail Penetration Layers of CLT Using Various Adhesives

\begin{tabular}{|c|c|c|c|c|c|}
\hline \multirow{2}{*}{ Type of CLT } & \multicolumn{5}{|c|}{ Nail Withdrawal Resistance (N/mm) } \\
\cline { 2 - 6 } & \multicolumn{2}{|c}{ Major Layer } & \multicolumn{2}{c|}{ Minor Layer } & Mixed Layers \\
\cline { 2 - 6 } & LH & LV & YH & YV & MV \\
\hline \multirow{2}{*}{ PR } & 15.80 & 42.70 & 28.30 & 72.50 & 47.40 \\
& $(0.08)$ & $(0.30)$ & $(0.32)$ & $(0.28)$ & $(0.33)$ \\
\hline \multirow{2}{*}{ PU } & 33.30 & 47.60 & 25.20 & 67.30 & 62.00 \\
& $(0.16)$ & $(0.18)$ & $(0.30)$ & $(0.19)$ & $(0.49)$ \\
\hline \multirow{2}{*}{ AU } & 30.80 & 48.20 & 27.20 & 61.10 & 53.20 \\
& $(0.69)$ & $(0.35)$ & $(0.20)$ & $(0.28)$ & $(0.27)$ \\
\hline
\end{tabular}

Table 5. Comparison of the Predicted and Experimental Values of Withdrawal Resistances

1) The value was predicted by NDS; ${ }^{2)}$ The value was predicted by Eq. 11 


\section{CONCLUSIONS}

Bearing and withdrawal resistance tests were used to evaluate the influence of the yellow poplar layer on the mechanical properties of the nail connections of a mixed crosslaminated timber (CLT) based on two domestic wood species. The following conclusions are drawn:

1. The bearing strength of the mixed CLT decreases with increasing yellow poplar laminas. The bearing strengths predicted by different formulae yielded results that were different to the experimental value of the lamina. The prediction formula for the mixed CLT with domestic species that considers the ratio of the bearing strengths and effective area ratios of the layers provided results that are similar to the actual measurement.

2. The nail withdrawal resistance of the yellow poplar lamina was measured to be 1.45times that of the Japanese larch. The nail withdrawal resistance of the mixed CLT in the direction vertical to the grain was increased due to the presence of the yellow poplar lamina. Therefore, the length of the nail connection for a mixed CLT should be optimized by ensuring that the nail penetration length reflects the characteristics of the layers.

\section{ACKNOWLEDGMENTS}

This study was supported by a research fellowship program through the National Institute of Forest Science (NIFoS), Korea.

\section{REFERENCES CITED}

American Wood Council (AWC) (2018). National Design Specification for Wood Construction, American Wood Council, Leesburg, VA, USA.

Broker, F. W., and Krause, H. A. (1991). "Preliminary investigations on the holding power of dynamically loaded wood-screws," Holz Roh-Werkst. 49(10), 381-384. DOI:.1007/BF02608920

Cha, J. K. (2002). "Nail withdrawal behavior for domestic small diameter logs," Mokjae Konghak 30(3), 104-108.

Eckelman, C. A. (1975). "Screw-holding performance in hardwoods and particleboard," Forest Prod. J. 25(6), 30-36.

Erol, K., and Sylvain, G. (2019). "Introduction to cross laminated timber," in: Canadian CLT Handbook, FPInnovations, Pointe Claire, Quebec, Canada.

Gahagan, J. M., and Scholten, J. A. (1938). Resistance of Wood to the Withdrawal of Nails (Unpublished Report), U. S. Department of Agriculture Forest Products Laboratory, Madison, WI, USA.

Hwang, K. H., and Park, B. S. (2008). "Lateral compression and dowel bearing property of Japanese larch grown in Korea," J. Korean Wood Sci. Technol. 36(3), 61-69. DOI: 10.5658/WOOD.2008.36.3.061

KDS 413305 (2016). “Connection design for timber structure,” Architectural Institute of Korea, Seoul, Korea. 
Kim, K. (2020). "Influence of layer arrangement on bonding and bending performances of cross-laminated timber using two different species," BioResources 15(3), 53285341. DOI: 10.15376/biores.15.3.5328-5341

Kim, K. H., and Hong, S. I. (2008). "Bearing properties of domestic larix glulam," J. Korean Wood Sci. Technol. 36(4), 93-101. DOI: 10.5658/WOOD.2008.36.4.093

Kim, K. H., and Jeon, W. S. (2019). "Evaluation of bonding performance of CLT using mixed species with polyurethane adhesive," J. Korean Furniture Soc. 30(4), 327-332.

KS F 2156 (2017). "Method of dowel-bearing strength test for wood and wood-based products," Korean Standards Association, Korean Agency for Technology and Standards, Ministry of Knowledge Economy, Gwacheon, Korea.

KS F ISO 9087 (2014). "Determination of nail and screw holding power under axial load application for wood," Korean Standards Association, Korean Agency for Technology and Standards, Ministry of Knowledge Economy, Gwacheon, Korea.

Larkin, B., Muszynski, L., Barbosa, A. R., Sinha, A., and Gupta, R. (2016). "Effective bonding parameters for hybrid cross-laminated timber (CLT) layups," in: $70^{\text {th }}$ International Convention, Forest Products Society, Portland, OR, USA

Mahdavifar, V., Barbosa, A. R., Sinha, A., Gupta, R., Muszynski, L., and Pryor, S. E. (2019). "Hysteretic response of metal connections on hybrid cross-laminated timber panels," J. Mater. Civil Eng. 145(1), 04018237. DOI: 10.1061/(ASCE)ST.1943541X.0002222

Mahdavifar, V., Sinha, A., Barbosa, A. R., Gupta, R., and Muszynski, L. (2018). "Lateral and withdrawal capacity of fasteners on hybrid cross-laminated timber panels," $J$. Mater. Civil Eng. 30(9), 04018226. DOI: 10.1061/(asce)mt.1943-5533.0002432

Mohammad, A. T., Saeed K. N. and Ghanbar E. (2009). "Withdrawal and lateral resistance of wood screw in beech, hornbeam and poplar," Eur. J. Wood Prod. 67, 135-140. DOI: 10.1007/s00107-008-0294-9

Moody, R. C., Hernandez, R., Davalos, J. F., and Sonti, S. S. (1993). "Yellow poplar glulam timber beam performance," Res. Pap. FPL-RP-520, U. S. Department of Agriculture Forest Products Laboratory, Madison, WI, USA.

Noguchi, M., and Sugihara, H. (1961). "Studies on static withdrawal resistance of nail: Effect of driving method and time after driving," Wood Res (Kyoto) 25, 1-13. http://hdl.handle.net/2433/52880

Norwahyuni, M. Y., Tahir, P. M., Lee, S. H., Khan, M. A., and James, R. M. S. (2019). "Mechanical and physical properties of cross-laminated timber made from Acacia mangium wood as function of adhesive types," J. Wood Sci. 65, 20. DOI: 10.1186/s10086-019-1799-z

Park, S. H., Kim, K. M., Pang, S. J., Kong, J. H., and Lee, S. J. (2017). "Evaluation of shear strength by direction of wood grain for Korean pine using PRF adhesive," $J$. Korean Wood Sci. Technol. 45(3), 243-249. DOI: 10.5658/WOOD.2017.45.3.243

Rammer, D. R., and Winistorfer, S. G. (2001). "Effect of moisture content on dowelbearing strength," Wood Fiber Sci. 33(1), 126-139.

Rammer, D. R., and Zelinka, S. L. (2004). Review of End Grain Nail Withdrawal Research (Gen. Tech. Rep. FPL-GTR-151), U. S. Department of Agriculture Forest Products Laboratory, Madison, WI, USA.

Sawata, K., and Yasumura, M. (2002). "Determination of embedding strength of wood for dowel-type fasteners," J. Wood Sci. 48, 138-146. DOI: 10.1007/BF00767291

Soltis, L. A., Hubbard, F. K., and Wilkinson, T. L. (1986). "Bearing strength of bolted timber joints," J. Struct. Eng. 112(9), 2141-2154. 
Whale, L. R. J., and Smith, I. (1989). "A method for measuring the embedding characteristics of wood and wood-based materials," Mater. Struct. 22, 403-410.

Wilkinson, T. L. (1991). Dowel Bearing Strength (Res. Pap. FPL-RP-505), U. S. Department of Agriculture Forest Products Laboratory, Madison, WI, USA.

Article submitted: November 30, 2020; Peer review completed: April 10, 2021; Revised version received and accepted: April 18, 2021; Published: April 20, 2021.

DOI: $10.15376 /$ biores.16.2.4027-4038 